Braz J Med Biol Res, January 2012, Volume 45(1) 49-57

doi: 10.1590/S0100-879X2011007500162

Transplantation of mononuclear cells from human umbilical cord blood promotes functional recovery after traumatic spinal cord injury in Wistar rats

L.P. Rodrigues, D. Iglesias, F.C. Nicola, D. Steffens, L. Valentim, A. Witczak, G. Zanatta, M. Achaval, P. Pranke and C.A. Netto

The Brazilian Journal of Medical and Biological Research is partially financed by

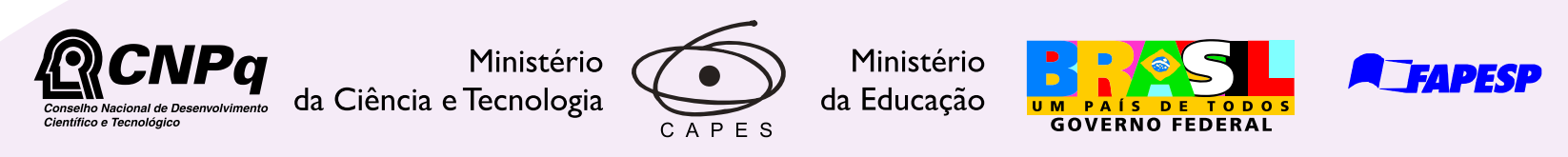

Institutional Sponsors
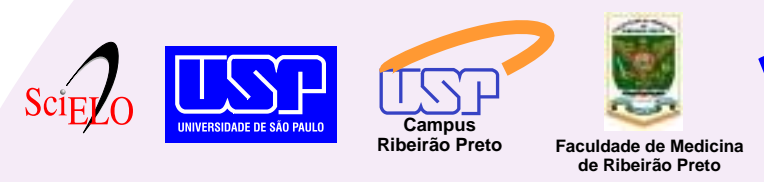

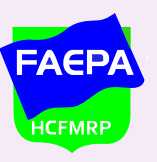

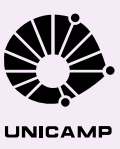

SHIMADZU

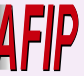

Associaçăo
Fundo de Incentivo
à Pesquisa

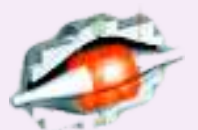

UNICAMP

lore High - Performance MS Orbitrap Technology analitica Thermo 


\title{
Transplantation of mononuclear cells from human umbilical cord blood promotes functional recovery after traumatic spinal cord injury in Wistar rats
}

\author{
L.P. Rodrigues ${ }^{1}$, D. Iglesias ${ }^{3}$, F.C. Nicola ${ }^{2}$, D. Steffens ${ }^{3}$, L. Valentim², \\ A. Witczak ${ }^{2}$, G. Zanatta ${ }^{2}$, M. Achaval ${ }^{4}$, P. Pranke ${ }^{3}$ and C.A. Netto ${ }^{2}$ \\ ${ }^{1}$ Programa de Pós-Graduação em Neurociências, \\ Universidade Federal do Rio Grande do Sul, Porto Alegre, RS, Brasil \\ ${ }^{2}$ Departamento de Bioquímica, Universidade Federal do Rio Grande do Sul, \\ Porto Alegre, RS, Brasil \\ ${ }^{3}$ Laboratório de Hematologia e Células-Tronco, Faculdade de Farmácia, \\ Universidade Federal do Rio Grande do Sul, Porto Alegre, RS, Brasil \\ ${ }^{4}$ Departamento de Ciências Morfológicas, \\ Universidade Federal do Rio Grande do Sul, Porto Alegre, RS, Brasil
}

\begin{abstract}
Cell transplantation is a promising experimental treatment for spinal cord injury. The aim of the present study was to evaluate the efficacy of mononuclear cells from human umbilical cord blood in promoting functional recovery when transplanted after a contusion spinal cord injury. Female Wistar rats (12 weeks old) were submitted to spinal injury with a MASCIS impactor and divided into 4 groups: control, surgical control, spinal cord injury, and one cell-treated lesion group. Mononuclear cells from umbilical cord blood of human male neonates were transplanted in two experiments: a) $1 \mathrm{~h}$ after surgery, into the injury site at a concentration of $5 \times 10^{6}$ cells diluted in $10 \mu \mathrm{L} 0.9 \% \mathrm{NaCl}(\mathrm{N}=8-10$ per group); b) into the cisterna magna, 9 days after lesion at a concentration of $5 \times 10^{6}$ cells diluted in $150 \mu \mathrm{L} 0.9 \% \mathrm{NaCl}(\mathrm{N}=12-14$ per group). The transplanted animals were immunosuppressed with cyclosporin-A (10 mg/kg per day). The BBB scale was used to evaluate motor behavior and the injury site was analyzed with immunofluorescent markers to label human transplanted cells, oligodendrocytes, neurons, and astrocytes. Spinal cord injury rats had $25 \%$ loss of cord tissue and cell treatment did not affect lesion extension. Transplanted cells survived in the injured area for 6 weeks after the procedure and both transplanted groups showed better motor recovery than the untreated ones $(P<0.05)$. The transplantation of mononuclear cells from human umbilical cord blood promoted functional recovery with no evidence of cell differentiation.
\end{abstract}

Key words: Spinal cord injury; Cell therapy; Functional recovery; Mononuclear cells; Human umbilical cord blood; MASCIS impactor

\section{Introduction}

Spinal cord injury affects mostly young and previously healthy subjects, resulting in temporary or permanent motor and sensory impairment and leading to chronic disability since there is no successful treatment for this condition $(1,2)$. Forty new cases per million persons per year are estimated and the last census of the Brazilian Institute of Geography and Statistics reported about 200,000 paraplegics (3).

After the initial compression trauma, the spinal cord suffers pathological changes involving two basic mechanisms: the primary events are hemorrhage, loss of microcirculation, vasospasm, and cell death occurring over a period of hours or days; most neuron and glia injury is complete within $24 \mathrm{~h}$, resulting in an expanding concentric lesion. The endogenous secondary lesion is downstream of the initial acute biochemical changes in calcium metabolism, lipid peroxidation and inflammatory events; oligodendrocyte loss occurs for several weeks, with consequent degeneration of white matter tracts $(4,5)$.

The most common and most frequently employed animal model for spinal cord injury was created in 1992 by Gruner et al. $(6,7)$ with the contusion spinal lesion produced by the Multicenter Animal Spinal Cord Injury Study

Correspondence: L.P. Rodrigues, Rua Ramiro Barcelos, 2600 - anexo, 90035-000 Porto Alegre, RS, Brasil. E-mail: Ipro@terra.com.br

Received June 8, 2011. Accepted November 28, 2011. Available online December 23, 2011. Published January 16, 2012. 
(MASCIS) impactor. According to McDonald and Howard (5), this method is particularly successful because of its high reproducibility.

Since functional recovery in patients after spinal cord injury is limited $(1,8)$, cell therapies have been considered as a treatment strategy $(9,10)$; one possible approach to the repair of spinal injury is the use of stem cells (11). Human umbilical cord blood is a source of bone marrow stem cells due to its hematopoietic and mesenchymal components (12). Stem cells present in human umbilical cord blood have been used in transplantation for treatment of blood disorders, as well as in experimental regenerative medicine for treating neurological disorders $(13,14)$. These cells are particularly interesting for transplantation because they are easy to obtain, to maintain and to expand under proper laboratory conditions (15).

Stem cells from human umbilical cord blood have been transplanted 5 days after injury in rats receiving spinal cord injury and the cells reached the area of injury after intravenous administration and behavioral deficits were improved (15). Harris (13) transplanted cord blood cells 5 days after injury and observed that they had differentiated into neural cells, improving axonal regeneration and motor function. CD34+ cells from human umbilical cord blood were implanted into the tail vein of rats immediately after a contusion injury, causing hindlimb functional recovery (16). In another report (17), rats with spinal lesions were treated with mononuclear cells from human umbilical cord blood 7 days after injury injected directly into the site of lesion. Transplanted animals had a significant functional improvement compared to control 6 weeks after transplantation and implanted cells survived and differentiated into oligodendrocytes and neurons.

The present study was designed to evaluate the effectiveness of mononuclear cells from human umbilical cord blood transplanted $1 \mathrm{~h}$ and 9 days after a contusion spinal cord injury in promoting recovery of functional deficits in adult Wistar rats. Our hypothesis was that transplantation of mononuclear cells would be able to promote motor deficit recovery and that injured rats transplanted 9 days after lesion would improve more than rats receiving cells $1 \mathrm{~h}$ after injury, because the resolution of the inflammatory process after 9 days would favor survival of transplanted cells. Two routes of administration were tested to allow for possible future clinical application.

\section{Material and Methods}

\section{Animals and spinal cord injury}

Adult female Wistar rats aged 3 months $(N=85,200$ $250 \mathrm{~g}$ body weight) were obtained from the Central Animal House of the Institute of Basic Health Sciences, Universidade Federal do Rio Grande do Sul. They were maintained in a temperature-controlled room $\left(21 \pm 2^{\circ} \mathrm{C}\right)$ on a 12/12-h light/ dark cycle, with food and water available ad libitum. All procedures were in accordance with the Guide for the Care and
Use of Laboratory Animals adopted by the National Institute of Health (USA) and with the Federation of Brazilian Societies for Experimental Biology (FESBE), and were approved by the University Research Ethics Committee, under No. 2008037/2010 - CEP UFRGS.

Rats suffered a moderate contusion spinal cord injury by the use of the MASCIS impactor (W.M. Keck Center for Collaborative Neuroscience, USA). Briefly, animals were anesthetized and laminectomy was performed at the T9 level. A 10-g weight was dropped from a height of $25 \mathrm{~mm}$ to produce the injury. The rats were then sutured and housed in individual home cages. The animals became motionless on their hindlimbs after surgery, remaining in a condition of paraplegia (7).

All animal care after spinal cord injury was provided in accordance with MASCIS protocols. An antibiotic (Baytril, Brazil) was administered up to 5 days post-injury to prevent urinary tract infection and rats were submitted to manual bladder expression twice a day during the first week or until they acquired voluntary control of this function (18).

\section{Transplantation of stem cells}

Mononuclear cells were obtained from human umbilical cord blood from male neonates. The cells were injected via two routes of administration at two distinct times: into the cisterna magna 9 days after injury and into the spinal cord $1 \mathrm{~h}$ after injury; $5 \times 10^{6}$ mononuclear cells diluted in $150 \mu \mathrm{L}$ $0.9 \% \mathrm{NaCl}$ were administered into the cisterna 9 days after injury and the same number of cells diluted in $10 \mu \mathrm{L} 0.9 \%$ $\mathrm{NaCl}$ were applied directly to the lesion site $1 \mathrm{~h}$ after injury.

Administration into the cisterna magna was as follows: the rat was placed prone on the stereotaxic instrument and the needle introduced between the occiput and high cervical spinal cord (first cervical vertebra); a 1-mL syringe with a $0.33-\mathrm{mm}$ gauge needle was used and the cell infusion was carried out slowly, taking approximately $30 \mathrm{~s}$. Rats from the group receiving cells into the injury site were kept anesthetized for $1 \mathrm{~h}$; a $1-\mathrm{mL}$ syringe with a $0.33-\mathrm{mm}$ gauge needle was used and the infusion time was of $30 \mathrm{~s}$. Neither cell reflux nor complications because of the local infusion were observed.

The fraction of mononuclear cells was obtained from term newborns after a 37-week gestation period and collected into blood bags containing citrate, phosphate and dextroseadenine (CPDA-1) anticoagulant. Mononuclear cells were isolated using density gradient centrifugation by Ficoll-Paque $1077 \mathrm{~g} / \mathrm{cm}^{2}$ (Amersham Pharmacia, USA) in Dulbecco's buffer (PBS, Gibco BRL, USA) used to dilute the blood (19), according to a previously established protocol (20). The procedure was approved by the Ethics Committee of Hospital Moinhos de Vento de Porto Alegre, under No. CEP/IEP-AHMV 2006/42, and samples were taken after mothers gave informed consent.

Only the animals receiving cell transplantation were immunosuppressed with cyclosporin-A treatment $(10 \mathrm{mg} / \mathrm{kg}$ per 
day) beginning the day before cell infusion and continued on 14 alternate days (21).

\section{Assessment of locomotor activity}

The functional deficits and functional recovery were evaluated in open-field locomotor activity using the Basso, Beatie, and Bresnahan scale (BBB) (22). Evaluations were performed 2 days before injury or laminectomy, 2 days after injury and weekly for 6 weeks after injury, for all experimental animals. Scale scoring was performed by videotaping the locomotor activity of animals in the open field. The records were observed and scores assigned by two evaluators blind to treatment status (22). Rats were evaluated 2 days after injury with the BBB scale and animals with spinal injury that did not present a paraplegia (zero score) and control animals that did not remain with normal locomotion (21 points) were excluded.

The scale assesses hindlimb motor function with scores ranging from 0 (complete paralysis) to 21 (normal locomotion). Animals were also classified according to the stage of motor function recovery: a) early phase of recovery, when the score is 1 to 7 (a few hindlimb joint movements), b) intermediate phase of recovery, with scores of 8 to 13 (hindlimb weight support), and c) later phase of recovery, when average total score is 14 to 21 (trunk stability and coordinated gait) (22).

\section{Experimental design}

Animals were divided into four groups: control (animals not exposed to any surgical procedure or treatment), surgical control (animals subjected to laminectomy surgery without cord injury), spinal cord injury (animals submitted to laminectomy and spinal cord injury), and the lesion group treated with cells (animals with spinal cord lesion treated with mononuclear cells obtained from human umbilical cord).

Two experiments were run: in the first $(\mathrm{N}=35)$ animals received the cell suspension $1 \mathrm{~h}$ after injury directly into the injury site; in the second, cells were transplanted into the cisterna magna 9 days after injury $(\mathrm{N}=50)$. For the first experiment, animals underwent laminectomy and lesion by the use of the MASCIS impactor; they were kept under anesthesia for another hour and then sutured and housed in individual cages following cell transplantation.

\section{Morphological analysis and immunofluorescence}

After completing behavioral assessment, i.e., 6 weeks after spinal cord injury or laminectomy surgery, rats were sacrificed for morphological analysis. They were anesthetized with $30 \%$ chloral hydrate $(10 \mathrm{~mL} / \mathrm{kg})$ and submitted to transcardiac perfusion with $0.9 \%$ saline followed by $4 \%$ formaldehyde. After this procedure, the spinal cord was removed from C5 to $L 5$ from the thoracic region and postfixed. The material was cryoprotected and frozen in isopentane cooled in liquid nitrogen until the completion of sectioning. For histological analysis, the thoracic region of the spinal cord was cut into $30-\mu \mathrm{m}$ sections with a cryostat (Leica, Germany) operating at a temperature of $-22^{\circ} \mathrm{C}$. Sections were then stained with cresyl violet and analyzed under light microscopy to permit an estimate of the thoracic spinal cord area using the Image-Pro Plus software (USA), version 6.0. The Cavalieri method (the sum of coronal areas of the thoracic spinal cord multiplied by the distance between each section) was used to calculate the volume of thoracic spinal cord area. All areas are reported as $\mathrm{mm}^{2}$ and volumes as $\mathrm{mm}^{3}(23)$.

Immunofluorescence analysis was performed on $50-\mu \mathrm{m}$ sections of representative areas of spinal cord injured tissue, by the method of Mestriner et al. (24). The following antibodies were used: a) anti-nucleus and mitotic cell antigen (NUMA) to label human cell nuclei (Millipore, USA; 1:50); b) glial fibrillary acidic protein (GFAP) to label astrocyte filaments (Sigma, USA; 1:200); c) chondroitin sulfate proteoglycan (NG2) to identify oligodendrocyte precursors (1:200, Millipore), and d) synaptophysin, a specific presynaptic marker for all neurons (1:200, Millipore) (24).

A laser scanning confocal microscope (Olympus FV 1000 , Japan) was used for the visualization of fluorescent labeling. Images of the Z-axis of the spinal cord injury site for each antibody were randomly selected using the Fluoview FV 1000 software (Olympus).

\section{Statistical analysis}

Both BBB scores and injury volumes were evaluated by one-way analysis of variance (ANOVA) for parametric data followed by the Duncan post hoc test. Data are reported as means \pm standard deviation and probability values of less than $5 \%$ were considered to be significant. All statistical analyses were performed using the Statistical software package running on a compatible personal computer.

\section{Results}

\section{Functional assessment}

Animals receiving mononuclear cells $1 \mathrm{~h}$ after injury by local administration in experiment 1 showed significant functional recovery from the second post-transplant week onwards compared to untreated animals $(P \leq 0.05)$. Figure $1 \mathrm{~A}$ reveals that control and sham groups differed from lesioned animals from day +2 and that at the end of the 6 th week lesioned rats showed a mean score of $13.3 \pm 3.4$ (intermediate stage of recovery; i.e., hindlimb weight support), although transplanted animals reached the late recovery phase (which means trunk stability and coordinated gait) already by 3 weeks after injury and ended with a score of $17.9 \pm 2.9$. This can be interpreted as an improvement in the recovery process after spinal cord injury when animals were treated while in the acute phase of injury ( $1 \mathrm{~h}$ after injury).

In the second experiment, with mononuclear cells transplanted 9 days after injury (Figure 1B), all groups showed the top score on the scale on day -2, i.e., 2 days before the injury, showing no previous locomotion deficit. Two days after contusion, all injured animals, treated or 
not, were completely paraplegic (no hindlimb movements). Figure $1 \mathrm{~B}$ shows that the lesioned rats differed significantly from both control groups from the 2nd day to 6 weeks after injury, which means that all animals subjected to the lesion procedure (spinal cord injury group) presented a significant change in walking performance.

Lesioned rats exhibited a spontaneous recovery of hindlimb motor performance, reaching a score of $11.6 \pm$ 3.3 by the end of 6 weeks, characterizing an intermediate stage of recovery. Transplanted animals reached a score of $14.9 \pm 2.8$, which is considered a late stage of recovery. These animals showed better functional out- come when compared with untreated injured animals, with significant differences in the 5th and 6th weeks after injury $(P \leq 0.05)$.

\section{Histological analysis and volume of the thoracic spinal cord}

Six weeks after injury, 5 animals per group per experiment were perfused and had their spinal cord removed for the estimate of thoracic spinal cord volume. Control groups (total and surgical treatment) presented a significantly different cord volume $\left(\left(581.14 \pm 57.77\right.\right.$ and $536.97 \pm 65.91 \mathrm{~mm}^{3}$, respectively) compared to the lesion $\left(435.85 \pm 39.14 \mathrm{~mm}^{3}\right)$
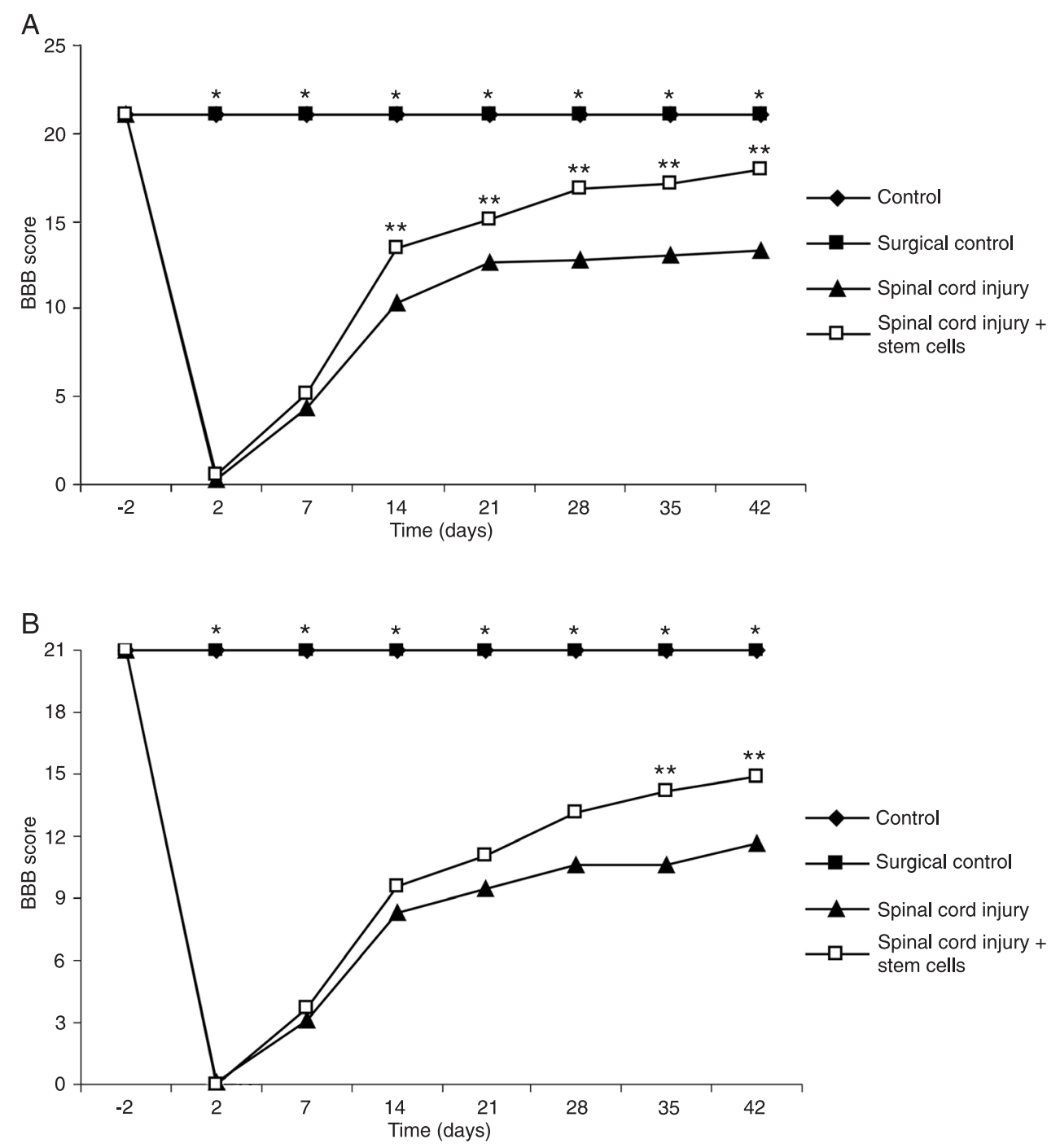

Figure 1. Basso, Beattie and Bresnahan (BBB) locomotor rating scale scores after treatment with mononuclear cells $1 \mathrm{~h}($ Panel $A)$ and 9 days $(P a n e / B)$ after rat spinal cord injury. Data are reported as means \pm SD for 8-14 rats in each group. BBB scale, scores range from 0 (complete paralysis) to 21 (normal gait). ${ }^{*} \mathrm{P} \leq 0.05$ for the control and sham groups compared to the injured and treated groups. ${ }^{* *} \mathrm{P} \leq 0.05$ for the injured group compared to the treated group (ANOVA followed by the Mann-Whitney test). 
and treated groups $\left(432.85 \pm 14.60\right.$ or $453.11 \pm 50.41 \mathrm{~mm}^{3}$; $\mathrm{P} \leq 0.05)$. Rats receiving the impactor contusion showed a $25 \%$ loss of cord tissue.

The two groups (Figure 2) treated with mononuclear cells from human umbilical cord blood cells administered $1 \mathrm{~h}\left(432.85 \pm 14.60 \mathrm{~mm}^{3}\right)$ or 9 days $\left(453.11 \pm 50.41 \mathrm{~mm}^{3}\right)$ after lesion did not differ from the lesioned group (435.85 \pm $39.14 \mathrm{~mm}^{3}$ ) regarding the volume of the thoracic spinal cord ( $P>0.05)$, demonstrating that mononuclear cell treatment, either in the cisterna or directly into the lesion site, did not affect the extension of morphological injury.

\section{Immunofluorescence}

To assess the ability of transplanted human cells to survive and migrate to the injury site after systemic administration, as well as to survive and remain in the area after local administration, NUMA was used to label the transplanted mononuclear cells. Image analysis by confocal microscopy showed that mononuclear cells, administered both into the cisterna magna ( 9 days) and directly into the lesion site (1 $\mathrm{h}$ after the lesion), survived in the transplanted animals up to 6 weeks after transplantation (Figure 3). The images obtained in this study show that more cells were present
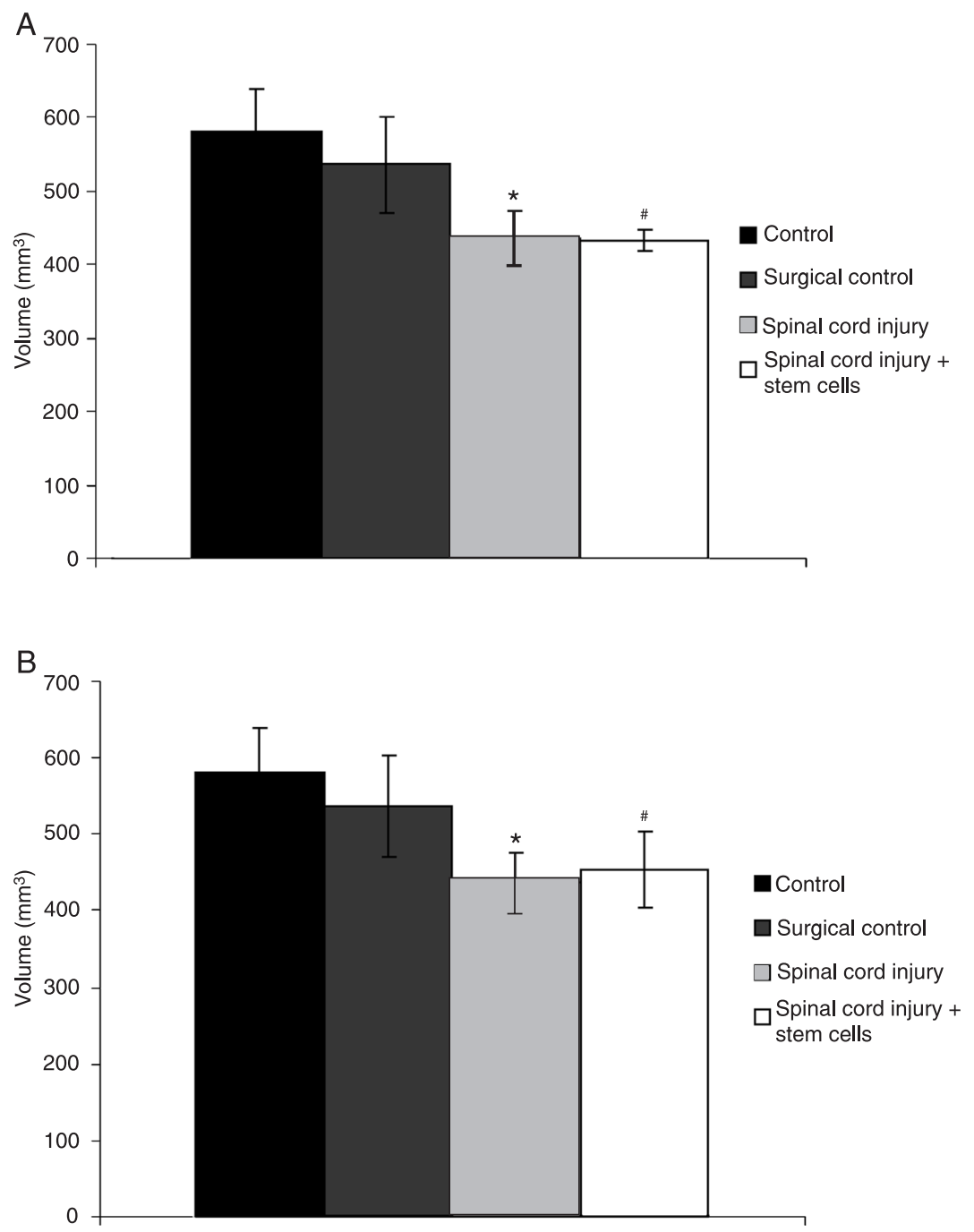

Figure 2. Volume of the thoracic spinal cord lesions of the group treated $1 \mathrm{~h}$ (Panel $A$ ) or 9 days $(P a n e / B)$ after spinal cord injury. Data are reported as means \pm SD for 5 rats in each group. ${ }^{*} \mathrm{P} \leq 0.05$, difference between the control groups and the spinal cord injured group (Mann-Whitney test). ${ }^{\mathrm{P}} \leq 0.05$, difference between the control groups and treated group (Duncan test). 
when injected locally at the injury site.

Spinal cord sections double-labeled with GFAP and NUMA antibodies showed that mononuclear cells at the injury site seem to be very closely associated with GFAPpositive astrocytes, although co-localization was not observed (Figures $4 \mathrm{C}$ and $5 \mathrm{C}$ ). Similar findings could be seen with NG2-positive cells and synaptophysin-positive cells, suggesting that the transplanted cells were present at the injury site, surrounded by host neurons and oligodendrocytes, but no co-localization of the antibodies could be dem-
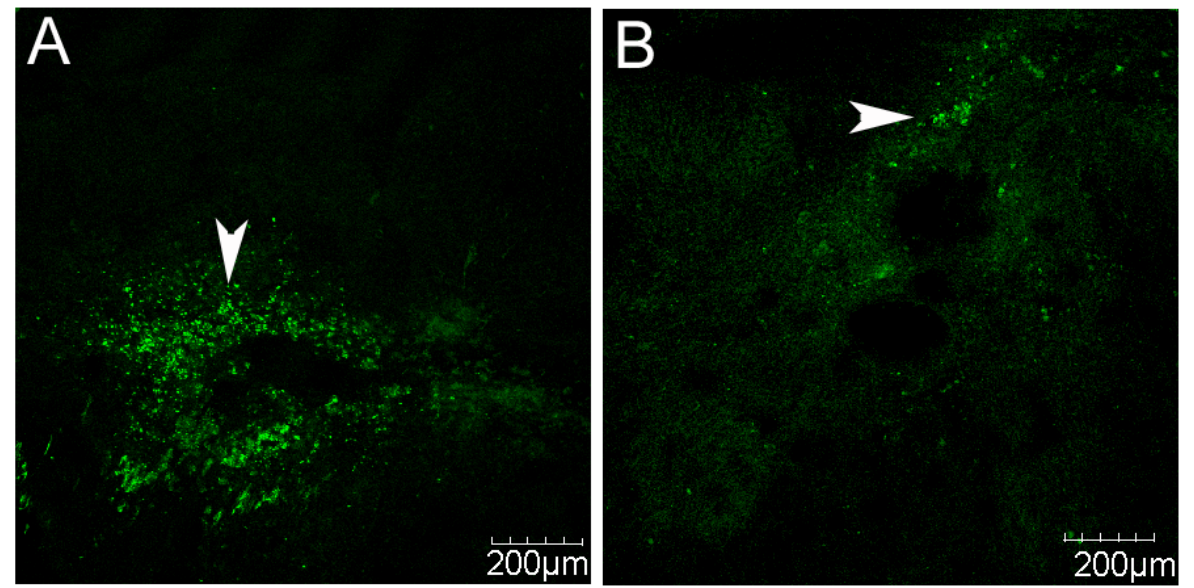

Figure 3. Identification of transplanted cells expressing human-specific anti-nucleus and mitotic cell antigen (NUMA). Mononuclear cells from human umbilical cord (arrowheads) present at the lesion site, at the T9 level, administered into the injury site $1 \mathrm{~h}(A)$ and into the cistern magna 9 days $(B)$ after the lesion.
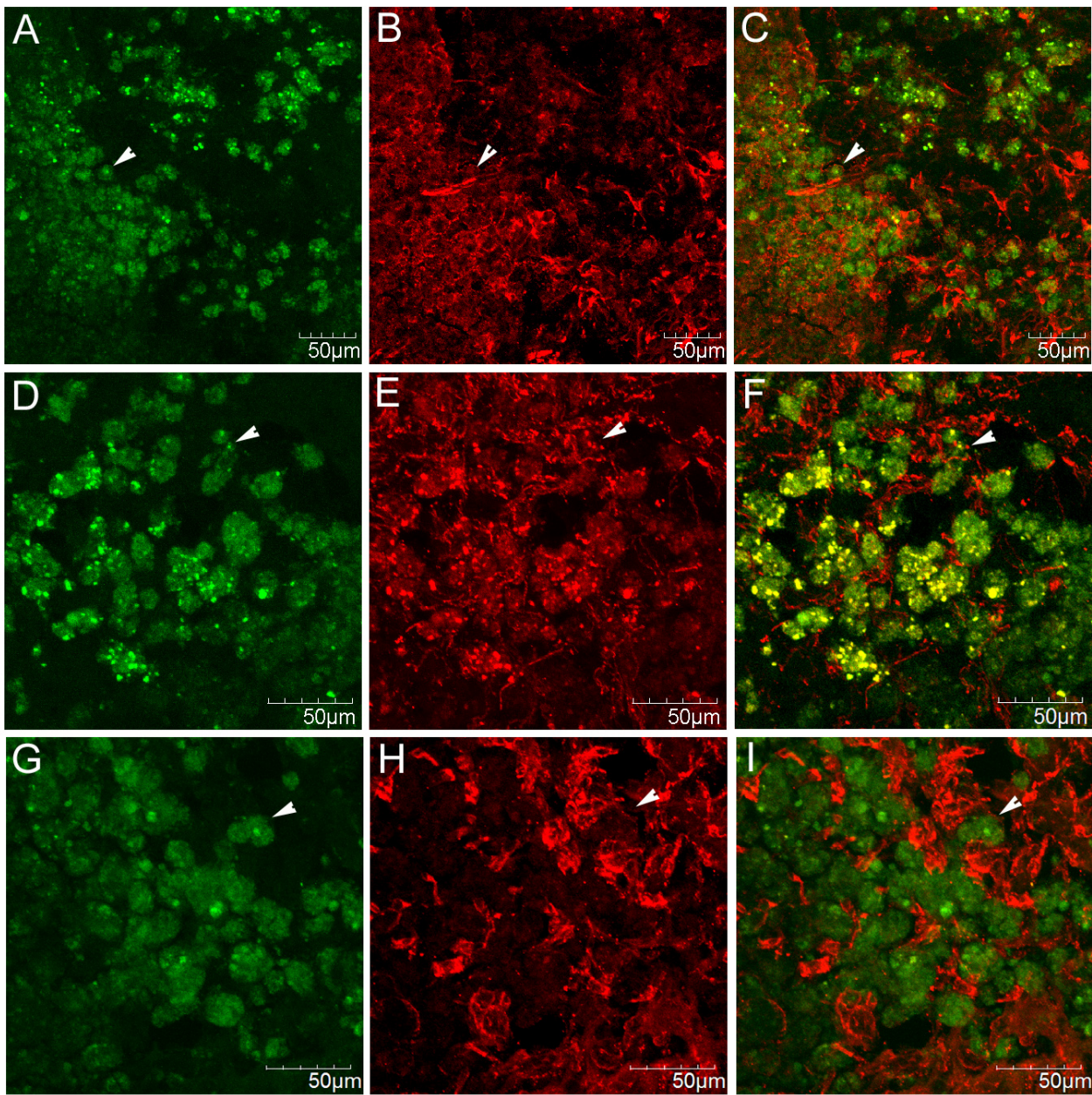

Figure 4. Immunofluorescence staining for antinucleus and mitotic cell antigen (NUMA) $(A, D, G)$, glial fibrillary acidic protein (GFAP) (B), synaptophysin $(E)$, and chondroitin sulfate proteoglycan (NG2) $(H)$ in sections of spinal cord at the T9 level of animals transplanted with mononuclear cells from umbilical cord blood $1 \mathrm{~h}$ after the lesion. Overlapping of the antibodies is represented as: $C$, NUMA (green) and GFAP (red); $F$, NUMA (green) and synaptophysin (red); I, NUMA (green) and chondroitin sulfate proteoglycan (NG2) (red). Arrowheads indicate: NUMA-positive cells $(A, D, G)$; positive cells when labeled with GFAP (B), synaptophysin $(E)$, and NG2 $(H)$; doublelabeling with NUMA and GFAP (C), synaptophysin $(F)$, and NG2 $(I)$. 

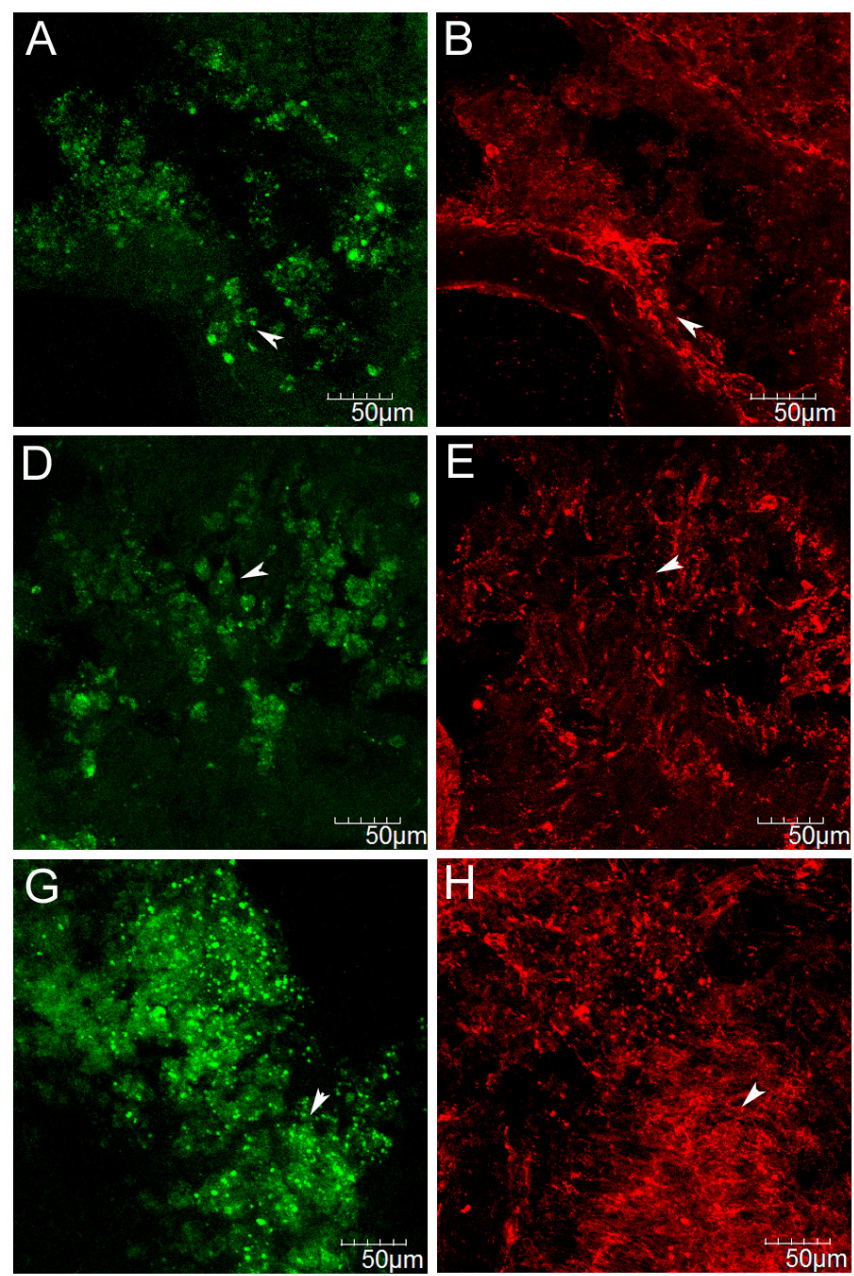
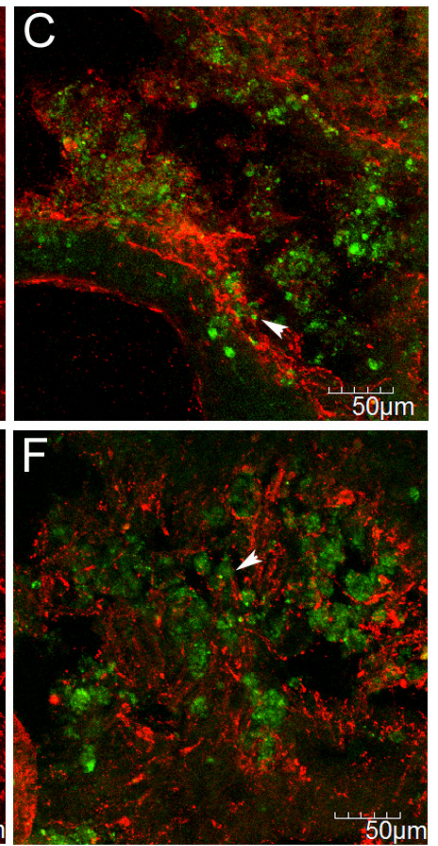

Figure 5. Immunofluorescence staining for nucleus and mitotic cell antigen (NUMA) $(A, D, G)$, glial fibrillary acidic protein (GFAP) $(B)$, synaptophysin $(E)$ and chondroitin sulfate proteoglican (NG2) $(H)$ in sections of spinal cord at the T9 level of animals transplanted with mononuclear cells from umbilical cord blood 9 days after the lesion. Overlapping of the antibodies is represented as: $C$, NUMA (green) and GFAP (red); $F$, NUMA (green) and synaptophysin (red); I, NUMA (green) and NG2 (red). Arrowheads indicate: NUMA-positive cells $(A, D, G)$; positive cells when labeled with GFAP (B), synaptophysin $(E)$, and NG2 $(H)$; double-labeling with NUMA and GFAP $(C)$, syn-

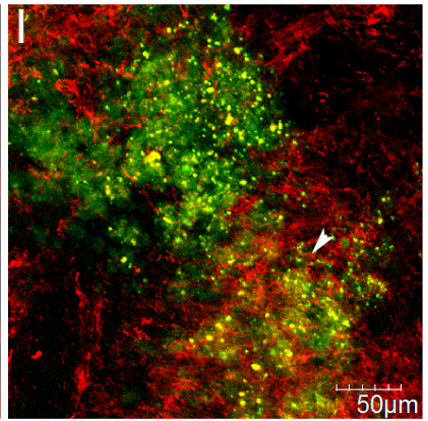
aptophysin $(F)$, and NG2 $(I)$. onstrated (Figures 4F,I and 5F,I). These findings suggest that, although the transplanted cells could be found at the injury site, even after 6 weeks of transplantation, they did not differentiate into glial nor neural cells.

\section{Discussion}

The present study demonstrated that treatment with mononuclear cells from human umbilical cord blood was able to promote functional recovery in rats subjected to spinal cord contusion when administered either into the cisterna magna or directly into the lesion site. Although both groups treated $1 \mathrm{~h}$ or 9 days after injury showed improvement of hindlimb motor function, coordination and gait, as measured by voluntary movements in the open-field, the best performance was shown by the group treated in the acute phase whose improvement was already evident beginning the 2 nd week after transplantation. Morphological analysis revealed a $25 \%$ loss of cord tissue volume in injured rats, irrespective of cell treatment, and immunofluorescence identified transplanted cells expressing the human-specific antibody (NUMA) at the injury site.

Several previous studies have demonstrated functional improvement after experimental spinal cord injury. The transplantation of bone marrow stem cells $(25,26)$ and of human mesenchymal stem cells $(27,28)$ into the injured spinal cord produced a significant functional recovery on the BBB scale.

Stem cells from human umbilical cord blood have also been described as a strategy of treatment when used in cell transplants to treat experimental spinal cord injury. Harris (13) transplanted stem cells from umbilical cord blood 5 days after spinal cord injury and found significant functional improvement compared with untreated animals. Dasari et al. (17) subjected the animals to a contusion injury and treated them with mononuclear cells from human umbilical cord blood 7 days after injury, directly at the injury site. The transplanted rats showed a significant functional improvement 6 weeks after transplantation.

Transplantation of mononuclear cells from human 
umbilical cord blood at the injury site (local administration) immediately after injury $(1 \mathrm{~h})$ yielded better functional results in the treatment of experimental spinal cord injury. Osaka et al. (10) also showed that when the administration of stem cells was performed $6 \mathrm{~h}, 1,3,7,14,21$, and 28 days after injury, more significant functional results were obtained when the stem cells were administered $6 \mathrm{~h}, 1$ and 3 days after injury, or even within the period of acute injury. Nandoe Tewarie et al. (28) observed that the presence of transplanted cells was higher 15 min and 3 days after injury compared with other times of administration.

In the present study, we observed that transplanted cells appeared to be present in greater amounts in animals receiving the infusion $1 \mathrm{~h}$ after lesion directly into the site of injury, compared to those that had cells administered 9 days after lesion in the cisterna magna. Considering that Dasari et al. (17) treated rats with spinal cord injury with mononuclear cells from human umbilical cord blood directly into the site 7 days after lesion and also observed a significant functional recovery after transplantation, these results support the idea that local administration is the best route for cell survival in the lesion environment.

Hematopoietic stem cells, such as those from the umbilical cord blood, secrete thrombopoietin and interleukin-11, cytokines that are essential for the survival and differentiation of neural progenitor cells (29). This may explain the greater functional recovery in animals treated with cells from human umbilical cord blood in this study, even though there was no differentiation of the transplanted cells, as revealed in Figures 4 and 5. Some investigators have shown that mononuclear cells form umbilical cord blood directly transplanted into the injury site after the lesion differentiated into oligodendrocytes (17). However, a study by Park et al. (30) showed that transplantation of stem cells caused functional improve-

\section{References}

1. Becker D, Sadowsky CL, McDonald JW. Restoring function after spinal cord injury. Neurologist 2003; 9: 1-15.

2. National Spinal Cord Injury Database (NSCID). http://www. spinalcord.uab.edu. Accessed September 12, 2010.

3. Brazilian Institute of Geography and Statistics (IBGE). Census of 2000. Rio de Janeiro [Internet document]. http:// www.ibge.gov.br/censo/text_censodemog.shtm. Accessed September 12, 2010.

4. Tator $\mathrm{CH}$, Fehlings MG. Review of the secondary injury theory of acute spinal cord trauma with emphasis on vascular mechanisms. J Neurosurg 1991; 75: 15-26.

5. McDonald JW, Howard MJ. Repairing the damaged spinal cord: a summary of our early success with embryonic stem cell transplantation and remyelination. Prog Brain Res 2002; 137: 299-309.

6. Basso DM, Beattie MS, Bresnahan JC. Graded histological and locomotor outcomes after spinal cord contusion using ment without differentiation into neurons or astrocytes, in agreement with our results.

The expression of the GFAP marker suggests glial cell proliferation in response to spinal cord injury, since the formation of a glial scar around the lesion is characterized by proliferation and hypertrophy of local astrocytes. This astrocytic response starts immediately after injury and persists over time $(1,8)$.

The potential of stem cell therapy is not necessarily related to the replacement of lost neurons. The most likely explanation for the beneficial effect of stem cells could be that transplanted cells migrate to the lesion environment and deliver factors that either promote the regeneration of nervous tissue or activate compensatory mechanisms and endogenous stem cells within the host tissue (25). This may explain the fact that, even though the transplanted cells failed to differentiate, treated animals showed a significant functional improvement. Implanted mononuclear cells from the human umbilical cord blood may have favored the endogenous response to secondary injury, promoting regeneration, i.e., these cells exerted a paracrine effect. Thus, transplanted mononuclear cells might have influenced the lesion environment to provide growth factors and cues for proliferation of progenitor cells or endogenous stem cells $(29,31)$, favoring the repair due to neurotrophic factors released by transplanted cells $(25,26)$.

\section{Acknowledgments}

We are grateful to Professor Rosália Mendez-Otero, from Universidade Federal do Rio de Janeiro, and to Professor Gerson Chadi, from Universidade de São Paulo, for their help with the experimental model, as well as with functional and morphological assessments. Research supported by CNPq.

the NYU weight-drop device versus transection. Exp Neurol 1996; 139: 244-256.

7. Gruner JA. A monitored contusion model of spinal cord injury in the rat. J Neurotrauma 1992; 9: 123-126.

8. Coutts M, Keirstead HS. Stem cells for the treatment of spinal cord injury. Exp Neurol 2008; 209: 368-377.

9. Horner PJ, Gage FH. Regenerating the damaged central nervous system. Nature 2000; 407: 963-970.

10. Osaka M, Honmou O, Murakami T, Nonaka T, Houkin K, Hamada $\mathrm{H}$, et al. Intravenous administration of mesenchymal stem cells derived from bone marrow after contusive spinal cord injury improves functional outcome. Brain Res 2010; 1343: 226-235.

11. McDonald JW, Becker D, Holekamp TF, Howard M, Liu S, Lu $A$, et al. Repair of the injured spinal cord and the potential of embryonic stem cell transplantation. J Neurotrauma 2004; 21: 383-393. 
12. Secco M, Zucconi E, Vieira NM, Fogaca LL, Cerqueira A, Carvalho MD, et al. Multipotent stem cells from umbilical cord: cord is richer than blood! Stem Cells 2008; 26: 146150.

13. Harris DT. Cord blood stem cells: a review of potential neurological applications. Stem Cell Rev 2008; 4: 269-274.

14. van de Ven C, Collins D, Bradley MB, Morris E, Cairo MS. The potential of umbilical cord blood multipotent stem cells for nonhematopoietic tissue and cell regeneration. Exp Hematol 2007; 35: 1753-1765.

15. Saporta S, Kim JJ, Willing AE, Fu ES, Davis CD, Sanberg PR. Human umbilical cord blood stem cells infusion in spinal cord injury: engraftment and beneficial influence on behavior. J Hematother Stem Cell Res 2003; 12: 271-278.

16. Kao $\mathrm{CH}$, Chen $\mathrm{SH}$, Chio CC, Lin MT. Human umbilical cord blood-derived CD34+ cells may attenuate spinal cord injury by stimulating vascular endothelial and neurotrophic factors. Shock 2008; 29: 49-55.

17. Dasari VR, Spomar DG, Li L, Gujrati M, Rao JS, Dinh DH. Umbilical cord blood stem cell mediated downregulation of fas improves functional recovery of rats after spinal cord injury. Neurochem Res 2008; 33: 134-149.

18. Weeks J, Hart RP. SCl-Base: an open-source spinal cord injury animal experimentation database. Lab Anim 2004; 33: 35-41.

19. Canabarro R, Sporleder H, Gomes T, Zanatta G, Scribel L, Freitas $\mathrm{F}$, et al. Immunophenotypic evaluation, and physiological and laboratory corelations of hematopoietic stem cells from umbilical cord blood. Biocell 2007; 31: 397-403.

20. Pranke P, Hendrikx J, Debnath G, Alespeiti G, Rubinstein $\mathrm{P}$, Nardi $\mathrm{N}$, et al. Immunophenotype of hematopoietic stem cells from placental/umbilical cord blood after culture. Braz J Med Biol Res 2005; 38: 1775-1789.

21. Andrews MR, Stelzner DJ. Evaluation of olfactory ensheathing and Schwann cells after implantation into a dorsal injury of adult rat spinal cord. J Neurotrauma 2007; 24: 1773-1792.

22. Basso DM, Beattie MS, Bresnahan JC. A sensitive and reliable locomotor rating scale for open field testing in rats. $J$ Neurotrauma 1995; 12: 1-21.
23. Arteni NS, Pereira LO, Rodrigues AL, Lavinsky D, Achaval ME, Netto CA. Lateralized and sex-dependent behavioral and morphological effects of unilateral neonatal cerebral hypoxia-ischemia in the rat. Behav Brain Res 2010; 210: 92-98.

24. Mestriner RG, Pagnussat AS, Boisserand LS, Valentim L, Netto CA. Skilled reaching training promotes astroglial changes and facilitated sensorimotor recovery after collagenase-induced intracerebral hemorrhage. Exp Neurol 2011; 227: 53-61.

25. Chopp M, Zhang XH, Li Y, Wang L, Chen J, Lu D, et al. Spinal cord injury in rat: treatment with bone marrow stromal cell transplantation. Neuroreport 2000; 11: 3001-3005.

26. Vaquero J, Zurita M, Oya S, Santos M. Cell therapy using bone marrow stromal cells in chronic paraplegic rats: systemic or local administration? Neurosci Lett 2006; 398: 129-134.

27. Lee KH, Suh-Kim H, Choi JS, Jeun SS, Kim EJ, Kim SS, et al. Human mesenchymal stem cell transplantation promotes functional recovery following acute spinal cord injury in rats. Acta Neurobiol Exp 2007; 67: 13-22.

28. Nandoe Tewarie RD, Hurtado A, Ritfeld GJ, Rahiem ST, Wendell DF, Barroso MM, et al. Bone marrow stromal cells elicit tissue sparing after acute but not delayed transplantation into the contused adult rat thoracic spinal cord. $J \mathrm{Neu}$ rotrauma 2009; 26: 2313-2322.

29. Urdzikova L, Jendelova P, Glogarova K, Burian M, Hajek $M$, Sykova E. Transplantation of bone marrow stem cells as well as mobilization by granulocyte-colony stimulating factor promotes recovery after spinal cord injury in rats. $J$ Neurotrauma 2006; 23: 1379-1391.

30. Park WB, Kim SY, Lee SH, Kim HW, Park JS, Hyun JK. The effect of mesenchymal stem cell transplantation on the recovery of bladder and hindlimb function after spinal cord contusion in rats. BMC Neurosci 2010; 11: 119.

31. Rossi SL, Nistor G, Wyatt T, Yin HZ, Poole AJ, Weiss JH, et al. Histological and functional benefit following transplantation of motor neuron progenitors to the injured rat spinal cord. PLoS One 2010; 5: e11852. 